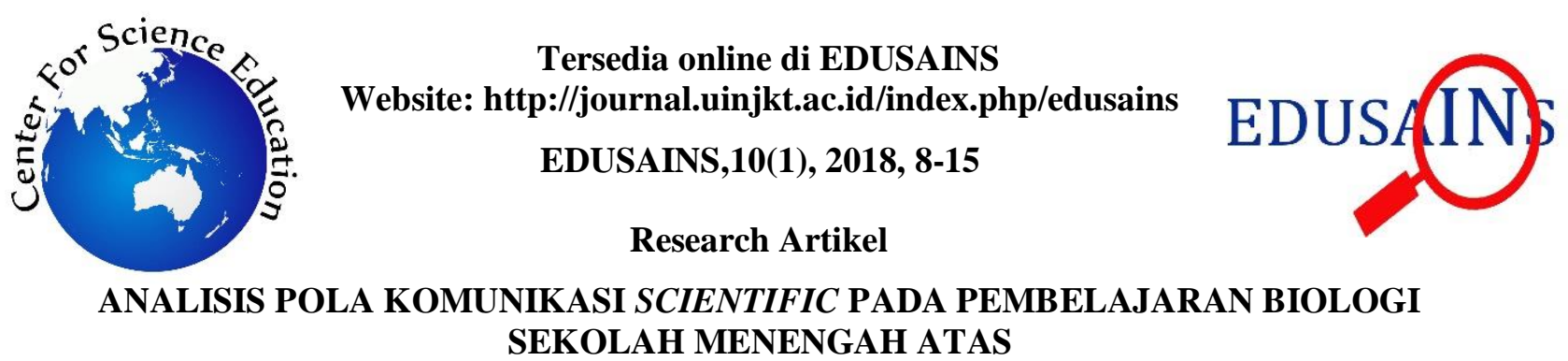

\title{
THE ANALYSIS OF SCIENTIFIC COMMUNICATION PATTERN IN HIGH SCHOOL BIOLOGY CLASS
}

\author{
Susana Mega Itsnaini ${ }^{1}$, Muzzazinah $^{1}$, Murni Ramli ${ }^{1}$, Yulianto $^{2}$, Anik Setyorini ${ }^{2}$ \\ ${ }^{1}$ Pendidikan Biologi FKIP Universitas Sebelas Maret, Surakarta, Indonesia, \\ ${ }^{2}$ SMA Negeri Gondangrejo, Karanganyar, Indonesia \\ megaitsnaini@gmail.com
}

\begin{abstract}
This research aims to study (1) the pattern of scientific communication in biology classes, and (2) the factors and reasons hinder the communication process during the learning process. This is a classroom observation conducted in two classes of grade XI Science of Gondangrejo High School, which were selected randomly. Fifty-five students participated, and two biology teachers had also been involved. The pattern of scientific communication was analyzed based on 10 times observations of both classes, then all communications recorded and analyzed based on VICS Flanders. The hindrances of communication were checked based on categorization introduced by Lunenburg, which consists of four: process, physics, semantic, and psycho social. The findings of the research shows that the pattern of communication is mostly balance between teacher and students, which is represented by region C G J K L M P R (52.43\%). Whilst, the area of teacher's domination is $24.79 \%$ (A B D E F H I ), and the area of student's domination scores $22.78 \%$ (N O S T). The pattern of scientific communication is two ways communication between teacher and students, but the frequency of student to initiate the communication remains low. The factors hinder the communication process are process barriers.
\end{abstract}

Keywords:scientific communication; communication pattern; VICS Flanders; communication difficulties

\begin{abstract}
Abstrak
Penelitian ini bertujuan mengetahui (1) pola komunikasi scientific pada pembelajaran biologi; (2) penyebab kendala komunikasi di kelas biologi. Penelitian ini adalah penelitian observasi kelas, yang dilakukan di dua kelas XI IPA SMA Negeri Gondangrejo yang dipilih secara acak. Siswa yang terlibat sejumlah 55 siswa, dan dua orang guru biologi juga menjadi partisipan. Data penelitian adalah proses komunikasi di dalam kelas yang diperoleh dari hasil observasi pembelajaran di dua kelas selama 10 kali kemudian seluruh komunikasi direkam dan dianalisa berdasarkan VICS Flanders. Kendala komunikasi dianalisis berdasarkan kategorisasi menurut Lunenburg (2010) yang terdiri 4 kategori, yaitu proses, fisik, semantik, dan psikososial. Hasil penelitian menunjukkan bahwa pola komunikasi yang terjadi adalah pola komunikasi seimbang antara guru dan siswa, dibuktikan dengan persentase wilayah C G J K L M P R $(52.43 \%$ ). Adapun persentase wilayah dominasi guru adalah $24.79 \%$ (A B D E F H I), dan presentase dominasi siswa adalah 22.78\% (N O S T). Pola komunikasi scientific yang terbentuk merupakan komunikasi dua arah, tetapi menunjukkan inisiasi komunikasi scientific siswa rendah. Kendala berkomunikasi di kelas umumya disebabkan oleh hambatan psikososial.
\end{abstract}

Kata Kunci:komunikasi scientific; pola komunikasi; VICS Flanders; kendala komunikasi

Permalink/DOI:http://dx.doi.org/10.15408/es.v10i1.6834

\section{PENDAHULUAN}

Komunikasi merupakan kegiatan bertukar informasi meliputi ide, gagasan, dan pikiran baik secara lisan maupun tulisan dengan tujuan membangun pemahaman yang sama (Velentzas \&
Broni, 2014). Menurut Nuryanto (2011), proses komunikasi dapat berjalan karena memiliki komponen-komponen komunikasi antara lain pengirim atau komunikator (sender), pesan (message), saluran (channel), penerima atau komunikan (receiver), umpan balik (feedback), dan 
aturan yang disepakati para pelaku komunikasi tentang bagaimana komunikasi itu akan dijalankan. Pola komunikasi diartikan sebagai bentuk atau pola hubungan dua orang atau lebih dalam proses pengiriman dan penerimaan informasi dengan cara yang tepat sehingga pesan yang dimaksud dapat dipahami.

Menurut Sudjana (2010), pola komunikasi terdiri dari tiga macam, yaitu pola komunikasi satu arah, pola komunikasi dua arah, dan pola komunikasi banyak arah. Menurut Lunenburg (2011), pola komunikasi memiliki lima bentuk antara lain : pola rantai; pola Y; pola roda; pola lingkaran; dan pola bintang. Terbentuknya pola komunikasi dapat disebabkan oleh empat hambatan, yaitu hambatan proses, hambatan fisik, hambatan semantik, dan hambatan psikososial (Lunenburg, 2010).

Pada kegiatan pembelajaran, komunikasi scientific merupakan komunikasi yang mencerminkan keaktifan belajar siswa mengkaji konsep pengetahuan dalam proses pembelajaran melalui bahasa verbal dan non verbal. Komunikasi scientific memiliki tujuan mentransfer pengetahuan dan pertukaran ide atau gagasan sehingga sangat berperan dalam proses pembelajaran (Sharifirad, Rezaeian, Jazini, \& Etemadi, 2012). Menurut Nielsen (2012), komunikasi merupakan bagian penting dari praktik science, karena pembelajar mampu membangun sebuah argumen yang menjadi pemahaman mendalam tentang pengetahuan sains melalui komunikasi.

Kemampuan komunikasi merupakan salah satu kompetensi yang diperlukan untuk menyampaikan gagasan dan pemikiran dalam berbagai konteks kehidupan (Chung, Yoo, Kim, Lee, \& Zeidler, 2014). Tugas dan peran guru bukan lagi sebagai pemberi informasi (transfer of knowledge), tetapi sebagai pendorong siswa belajar (stimulation of learning) agar dapat mengonstruksi sendiri pengetahuan melalui berbagai aktivitas termasuk aspek berkomunikasi (Umar, 2012). Dalam penelitian yang dilakukan oleh Inamullah, Hussain, \& Din (2008), yaitu mengeksplorasi interaksi verbal guru dan siswa di sekolah menengah, menunjukkan hasil bahwa persentase guru berbicara di dalam kelas pada sekolah menengah melebihi dua pertiga dari total waktu pembelajaran di kelas, artinya komunikasi di kelas didominasi oleh guru. Kondisi ideal pada proses pembelajaran terkait dengan keterampilan komunikasi menurut Mulyasa (2006), adalah terjadinya interaksi yang baik dan efektif antara siswa dan guru, yaitu interaksi yang tidak berjalan hanya satu arah. Selain itu, juga terdapat interaksi antarsiswa serta interaksi siswa dengan lingkungan pembelajaran yang meliputi aktivitas siswa secara fisik dan sosial sehingga mampu untuk memberikan pemecahan masalah.

Salah satu model pemetaan komunikasi yang dapat digunakan untuk mengetahui pola komunikasi scientific siswa dalam pembelajaran biologi adalah VICS Flanders (Verbal Interaction Category System). Model VICS Flanders dapat memberikan informasi yang akurat tentang aktivitas belajar dan interaksi antara siswa dan guru (Roshayanti, 2010). Melalui VICS Flanders dapat diketahui dominasi guru dalam kelas, keaktifan siswa saat proses pembelajaran, sejauh mana guru memusat pada kegiatan akademik, sikap guru bertindak adil dalam menjawab atau memberikan pertanyaan, dan derajat terikatnya siswa dalam kegiatan akademik (Syaban, 2003).

Terdapat beberapa penelitian yang berkaitan dengan penerapan VICS Flanders untuk mengetahui pola komunikasi dalam proses pembelajaran, diantaranya penelitian yang dilakukan oleh Winarni, Santosa, \& Ramli (2016) tentang pengaruh model Discovery Learning terhadap aktivitas oral siswa. Hasil penelitian tersebut mengungkapkan bahwa terbentuk pola komunikasi dua arah antara siswa dan guru, terdapat peningkatan oral activities siswa dan penurunan dominasi guru pada proses pembelajaran.

Penelitian relevan lainnya dilakukan oleh Tyagi \& Mittal (2013) yang menganalisis komunikasi verbal guru dan siswa menggunakan metode Flanders melalui observasi kelas menunjukkan hasil bahwa guru lebih mendominasi komunikasi daripada siswa. Hasil lain menunjukkan bahwa frekuensi bicara guru perempuan lebih besar dibanding frekuensi bicara guru laki-laki. Frekuensi bicara guru perempuan sebesar $85,85 \%$, sedangkan frekuensi bicara guru laki-laki sebesar 79,99\%. 
Penelitian relevan tersebut menunjukkan hasil bahwa pola komunikasi verbal dalam pembelajaran di kelas dapat diukur menggunakan VICS Flanders, akan tetapi belum mengungkapkan faktor-faktor penyebab terbentuknya pola komunikasi. Oleh karena itu, diperlukan adanya penelitian mengenai analisis pola komunikasi verbal dalam proses pembelajaran menggunakan VICS Flanders yang disertai dengan analisis faktorfaktor yang menyebabkan pola komunikasi scientific dalam proses pembelajaran. Komunikasi yang dianalisis adalah komunikasi scientific yaitu komunikasi yang mencerminkan keaktifan belajar siswa mengkaji konsep pengetahuan dalam proses pembelajaran melalui bahasa verbal.

Penelitian ini dikembangkan dengan rumusan masalah sebagai berikut: (1) Bagaimanakah pola komunikasi scientific pada pembelajaran biologi?; (2) Apakah penyebab terbentuk pola komunikasi scientific pada pembelajaran biologi?

\section{METODE}

Penelitian observasi kelas dilaksanakan untuk mengetahui pola komunikasi scientific dan penyebab kendala komunikasi scientific pada pembelajaran biologi. Penelitian dilakukan di kelas XI IPA 1 dan XI IPA 4 SMA Negeri Gondangrejo semester genap tahun pelajaran 2016/1017. Kedua kelas adalah kelas peminatan IPA, yang dipilih secara acak (random sampling) dari 23 kelas yang ada di SMA tersebut. Subjek penelitian berjumlah 55 siswa terdiri dari 43 siswa perempuan dan 12 siswa laki-laki dengan kemampuan akademik yang berbeda-beda. Secara detil, kelas IPA 1 terdiri dari 25 siswa, dan kelas IPA 4 terdiri dari 30 siswa. Adapun guru biologi yang terlibat terdiri dari dua orang berusia 46 tahun dan 40 tahun berjenis kelamin laki-laki dan perempuan. Keduanya memiliki pengalaman mengajar biologi di SMA selama lebih dari 15 tahun. Siswa-siswa dan guru yang terlibat dalam penelitian ini telah dimintai persetujuan keterlibatannya, dan kedua belah pihak telah menyatakan persetujuannya melalui pernyataan tertulis.

Penelitian ini terdiri dari dua tahap pengambilan data, yaitu tahap pertama adalah untuk mendapatkan data pemetaan pola komunikasi saintifik di kelas melalui kegiatan observasi.
Observasi berlangsung selama tiga bulan, yaitu dari bulan Februari sampai April 2017. Observasi dan pengukuran dilakukan sebanyak 10 kali pengulangan dengan subjek materi yang berbeda pada setiap pertemuan. Pengulangan mengikuti jadwal materi di kelas masing-masing. Semua proses komunikasi di dalam kelas selama pembelajaran dicatat dan direkam secara audio. Kesepuluh hasil pemetaan dianalisis. Data penelitian pola komunikasi scientific diperoleh melalui pengisian lembar observasi VICS Flanders berdasarkan pengamatan komunikasi scientific guru dan siswa pada pembelajaran biologi.

Analisis data pada lembar observasi VICS Flanders dilakukan dengan cara melakukan reduksi pada percakapan yang tidak saintifik, dan selanjutnya semua percakapan diberi koding. Setelah koding berhasil dibuat, langkah selanjutnya adalah memasangkan hasil koding pada Skema VICS Flanders (Gambar 1).

\begin{tabular}{|c|c|c|c|c|}
\hline \multicolumn{2}{|c|}{ DIMENSI } & \multicolumn{2}{|c|}{ NO } & \multirow{2}{*}{$\begin{array}{l}\text { KATEGORI DAN DESKRIPSI } \\
\text { Menyajikan informasi atau pendapat, } \\
\text { digunakan apabila guru menyajikan } \\
\text { konten, fakta atau opini, ekplanasi, } \\
\text { diskusi, dan pertanyaan retorika juga } \\
\text { termasuk. }\end{array}$} \\
\hline & & 1 & & \\
\hline & & 2 & & $\begin{array}{l}\text { Memberikan arahan, digunakan apabila } \\
\text { guru memberikan perintah, arahan, atau } \\
\text { petunjuk agar siswa melakukan } \\
\text { mematuhinya. }\end{array}$ \\
\hline & & 3 & & $\begin{array}{l}\text { Mengajukan pertanyaan sempit, } \\
\text { digunakan apabila jawaban pertanyaan } \\
\text { diperkirakan mudah dijawab oleh siswa. }\end{array}$ \\
\hline & $\underset{\dot{\Sigma}}{\stackrel{\pi}{\Xi}}$ & \multicolumn{2}{|c|}{4} & $\begin{array}{l}\text { Mengajukan pertanyaan luas, digunakan } \\
\text { bilamana suatu pertanyaan agak terbuka } \\
\text { menghendaki pemikiran, atau } \\
\text { mengesankan sebagai suatu pendapat atau } \\
\text { perasaan. }\end{array}$ \\
\hline & \multirow[b]{5}{*}{ 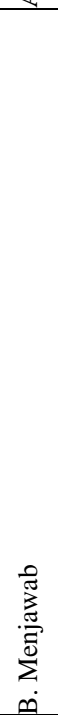 } & \multirow[b]{3}{*}{ 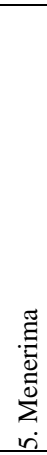 } & $5 a$ & $\begin{array}{l}\text { Menerima pendapat, digunakan apabila } \\
\text { guru menerima, memantulkan, } \\
\text { menjelaskan, atau memuji pendapat } \\
\text { pembelajar. Jika guru mengulangi, } \\
\text { menyimpulkan, atau mengomentari } \\
\text { pendapat siswa. }\end{array}$ \\
\hline & & & $5 b$ & $\begin{array}{l}\text { Menerima prilaku, digunakan apabila guru } \\
\text { menerima dan menggiatkan prilaku. }\end{array}$ \\
\hline & & & $5 c$ & $\begin{array}{l}\text { Menerima perasaan, digunakan jika guru } \\
\text { merefleksikan perasaan pembelajar, atau } \\
\text { menjawab } \quad \text { perasaan } \\
\text { menyenangkan. }\end{array}$ \\
\hline & & \multirow[b]{2}{*}{$\frac{\frac{y}{J}}{0}$} & $6 a$ & $\begin{array}{l}\text { Menolak ide, digunakan apabila guru } \\
\text { menolak, mengkritik, mengabaikan, atau } \\
\text { kurang menggiatkan ide siswa. }\end{array}$ \\
\hline 㞼 & & & $6 b$ & $\begin{array}{l}\text { Menolak prilaku, digunakan apabila guru } \\
\text { mengomentari atau mengeritik untuk } \\
\text { menekan prilaku siswa yang kurang } \\
\text { diterima. }\end{array}$ \\
\hline
\end{tabular}




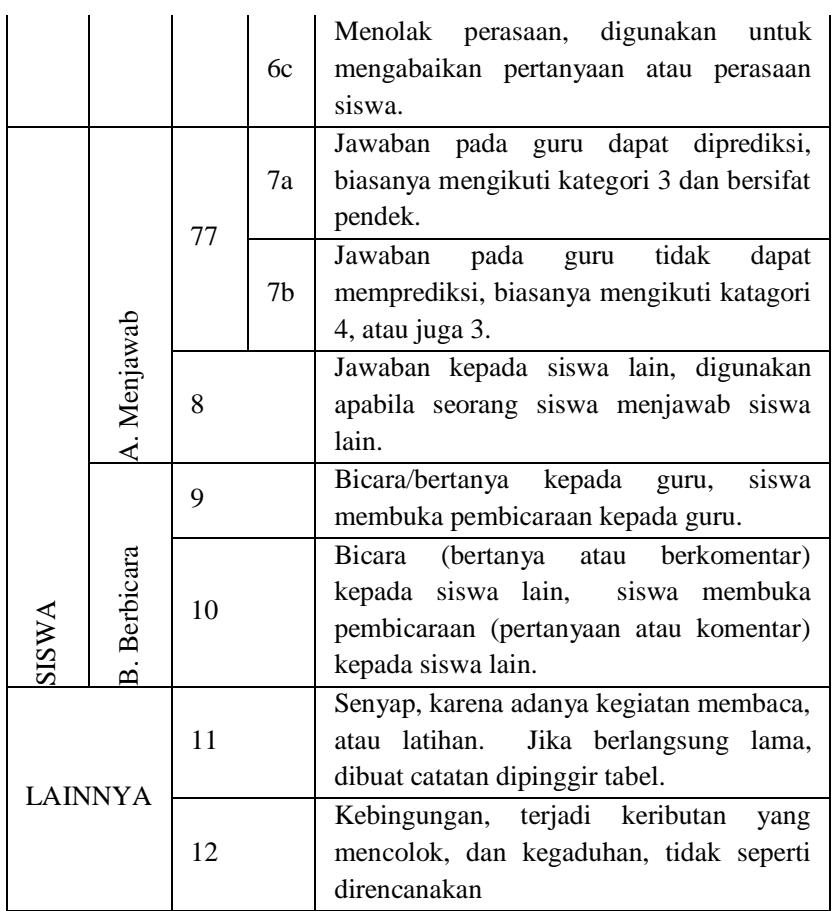

(Sumber: Herlanti, 2006)

\section{Gambar 1. Kategori VICS Flanders}

Pemasangan hasil koding dapat dilakukan dengan cara mengambil sepasang data pada bagian awal kemudian bagian kedua dipasangkan pada data berikutnya, demikian seterusnya. Setiap pasangan kemudian dipetakan dengan meletakkan pada matriks hubungan antar kategori VICS yang disajikan pada Gambar 2.

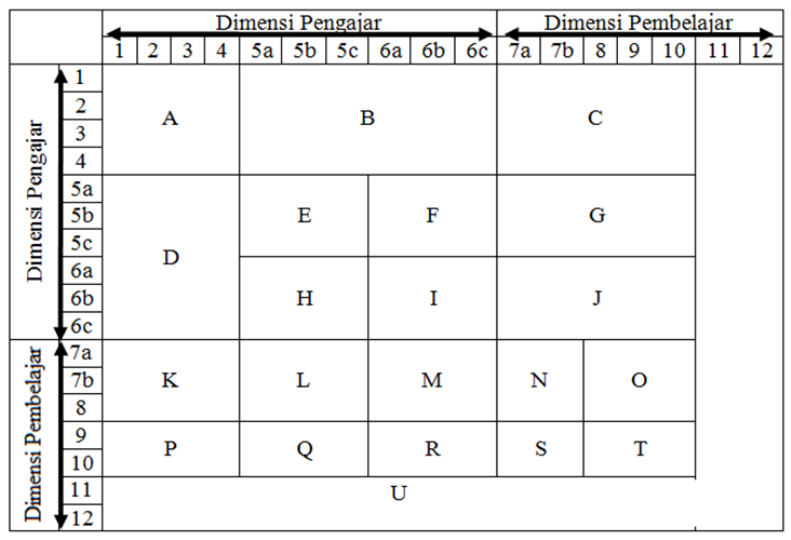

(Sumber: Herlanti, 2006)

\section{Gambar 2. Matriks Hubungan Antar Kategori VICS}

Analisis data dilakukan dengan menghitung persentase frekuensi disetiap daerah yang terdapat pada matriks hubungan kategori VICS (Winarni et al., 2016). Jika frekuensi interaksi pada wilayah A, B, D, E, F, H, I sangat tinggi dibandingkan dengan daerah lainnya, ini menunjukan bahwa guru sangat mendominasi selama proses belajar mengajar berlangsung. Adapun wilayah C, G, J, K, L, M, P,
$\mathrm{R}$ menunjukan wilayah dimana terjadi proses dialog yang bersifat umpan balik terjadi antara guru dan siswa, sedangkan wilayah $\mathrm{N}, \mathrm{O}, \mathrm{S}, \mathrm{T}$ menunjukan wilayah aktifitas antar siswa, wilayah ini memiliki frekuensi yang tinggi jika pembelajaran yang dilakukan oleh guru berupa diskusi kelompok dengan siswa sebagai presentatornya (Herlanti, 2006).

Penelitian tahap kedua adalah untuk memperoleh data faktor penyebab terhambatnya proses komunikasi yang diperoleh melalui wawancara non struktur kepada sembilan siswa yang dipilih secara purposive di kedua kelas amatan, dan kedua guru. Pemilihan purposive dilakukan pada kelompok siswa yang dalam pemetaan komunikasi di penelitian tahap I menunjukkan performa komunikasi yang lemah. Sedangkan kedua guru diwawancarai untuk mendapatkan informasi tentang pandangannya terkait hambatan komunikasi yang terjadi di kelas.

Analisis wawancara dilakukan dengan melakukan koding pada kata-kata kunci yang mengarah pada kategorisasi hambatan komunikasi berdasarkan Lunenburg (2010). Kata-kata kunci tersebut antara lain pada; hambatan proses meliputi kesulitan menyampaikan dan menerima pesan, respon komunikan, serta kecukupan waktu pembelajaran; hambatan fisik meliputi posisi tempat duduk, penggunaan sosial media, serta kondisi fisik lingkungan tempat tinggal siswa; hambatan semantik meliputi penggunaan bahasa di rumah, di sekolah, dan istilah berbahasa latin; dan hambatan psikososial meliputi karakter atau kebiasaan belajar siswa, suasana belajar di kelas, dan suasana belajar di rumah.

\section{HASIL DAN PEMBAHASAN}

\section{Pola Komunikasi Scientific pada Pembelajaran Biologi}

Hasil penelitian terhadap pola komunikasi scientific pada pembelajaran biologi dengan menggunakan indikator Verbal Interaction Categorical System (VICS) Flanders siswa kelas XI IPA 1 dan XI IPA 4 SMA Negeri Gondangrejo pada observasi I, II, III, IV, V, VI, VIII, VIII, IX, dan $\mathrm{X}$ menunjukkan adanya pola yang berbeda (Tabel 1). 
Tabel 1. Perbandingan Pengelompokan Wilayah Komunikasi

\begin{tabular}{|c|c|c|c|c|c|}
\hline \multirow{2}{*}{ No } & \multirow{2}{*}{ Tanggal } & \multirow{2}{*}{ Kelas } & \multicolumn{3}{|c|}{$\begin{array}{c}\text { Pengelompokan } \\
\text { Wilayah Komunikasi }(\%)\end{array}$} \\
\hline & & & $\begin{array}{c}\text { A B D E F } \\
\text { H I }\end{array}$ & $\begin{array}{c}\text { C G J K L } \\
\text { MP R }\end{array}$ & $\underset{T}{\operatorname{NOS}}$ \\
\hline 1 & 23-Feb-17 & XI IPA 4 & 8.96 & 20.90 & 70.15 \\
\hline 2 & 2-Mar-17 & XI IPA 4 & 16.85 & 56.18 & 26.97 \\
\hline 3 & 3-Mar-17 & XI IPA 1 & 10.71 & 50.00 & 39.29 \\
\hline 4 & 9-Mar-17 & XI IPA 4 & 30.53 & 52.63 & 16.84 \\
\hline 5 & 13-Mar-17 & XI IPA 1 & 22.45 & 55.10 & 22.45 \\
\hline 6 & 27-Mar-17 & XI IPA 1 & 33.33 & 66.67 & 0.00 \\
\hline 7 & 29-Mar-17 & XI IPA 4 & 22.03 & 67.80 & 10.17 \\
\hline 8 & 30-Mar-17 & XI IPA 1 & 24.32 & 51.35 & 24.32 \\
\hline 9 & 17-Apr-17 & XI IPA 1 & 43.40 & 56.60 & 0.00 \\
\hline 10 & 19-Apr-17 & XI IPA 4 & 35.29 & 47.06 & 17.65 \\
\hline \multicolumn{3}{|c|}{ Rata-rata } & 24.79 & 52.43 & 22.78 \\
\hline
\end{tabular}

Keterangan:

- Jika frekuensi interaksi komunikasi pada wilayah A, B, D, E, F, H, I sangat tinggi dibandingkan dengan daerah lainnya,menunjukan bahwa guru sangat mendominasi selama proses belajar mengajar berlangsung

- Jika frekuensi interaksi komunikasi pada wilayah $\mathrm{C}, \mathrm{G}, \mathrm{J}, \mathrm{K}, \mathrm{L}, \mathrm{M}, \mathrm{P}, \mathrm{R}$ sangat tinggi dibandingkan dengan daerah lainnya, menunjukan bahwa terjadi proses dialog yang bersifat umpan balik terjadi antara guru dan siswa

- Jika frekuensi interaksi komunikasi pada wilayah $\mathrm{N}, \mathrm{O}, \mathrm{S}, \mathrm{T}$ sangat tinggi dibandingkan dengan daerah lainnya, menunjukan bahwa terjadi aktifitas antarsiswa, wilayah ini memiliki frekuensi yang tinggi jika pembelajaran yang dilakukan oleh guru berupa diskusi kelompok dengan siswa sebagai presentatornya

Dengan persentase dari rata-rata daerah berbeda-beda (Gambar 3). Persentase pengelompokan wilayah komunikasi terbesar berada pada wilayah $\mathrm{C}, \mathrm{G}, \mathrm{J}, \mathrm{K}, \mathrm{L}, \mathrm{M}, \mathrm{P}, \mathrm{R}$ (52.43\%) sehingga menunjukkan bahwa frekuensi komunikasi antara guru dan siswa pada wilayah tersebut sangat tinggi. Pola komunikasi scientific yang terbentuk pada pembelajaran biologi dari sepuluh kali observasi kelas adalah seimbang antara guru dan siswa, artinya tidak terdapat dominasi komunikasi oleh guru maupun siswa. Hal tersebut ditandai dengan terjadinya proses dialog yang bersifat umpan balik antara guru dan siswa.

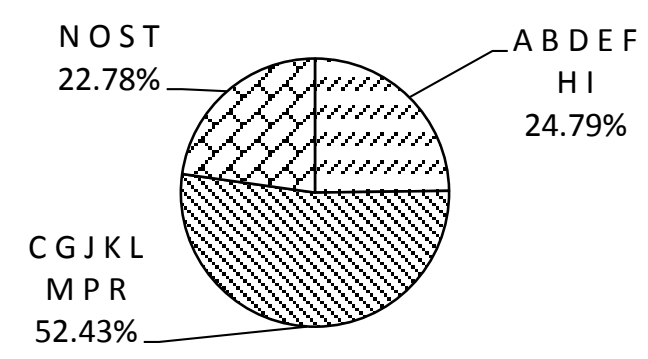

$$
\begin{gathered}
\text { Gambar 3. Persentase Perbandingan Pengelompokan } \\
\text { Wilayah Komunikasi }
\end{gathered}
$$

Pola komunikasi scientific yang terbentuk di dalam pembelajaran biologi merupakan komunikasi dua arah. Menurut Sudjana (2010), komunikasi dua arah terjadi jika guru dan siswa memiliki dominasi komunikasi yang sama dalam proses pembelajaran, sehingga terdapat reaksi timbal balik. Pola komunikasi scientific yang terbentuk menyerupai pola komunikasi bintang, yaitu setiap anggota dapat berkomunikasi dengan anggota lain secara bebas (Lunenburg, 2011).

Walaupun guru dan siswa dapat berkomunikasi secara bebas, persentase pengelompokan wilayah komunikasi pada wilayah A B D E F H I (24.79\%) lebih besar daripada wilayah $\mathrm{N} \quad \mathrm{O} \quad \mathrm{S} \quad \mathrm{T}$ (22.78\%). Hal tersebut menunjukkan bahwa komunikasi scientific guru lebih mendominasi selama proses pembelajaran berlangsung sehingga inisiasi komunikasi scientific siswa rendah. Rendahnya inisiasi komunikasi scientific siswa menunjukkan bahwa siswa kurang aktif berkomunikasi dalam proses pembelajaran.

\section{Penyebab Terbentuk Pola Komunikasi Scientific pada Pembelajaran Biologi}

Pola komunikasi scientific pada pembelajaran biologi yang terbentuk merupakan komunikasi dua arah karena terdapat reaksi timbal balik yang tinggi antara guru dan siswa selama proses pembelajaran. Akan tetapi, inisiasi komunikasi scientific siswa rendah. Hal tersebut dapat disebabkan oleh hambatan-hambatan komunikasi, sehingga mengakibatkan kesulitan dalam proses komunikasi scientific siswa. Menurut Lunenburg (2010), terdapat empat tipe hambatan komunikasi, yaitu hambatan proses, hambatan fisik, hambatan semantik, dan hambatan psikososial. 
Berdasarkan hasil wawancara siswa A4-S18, A4-S29, A4-S7, A4-S26, A4-S25, A4-S28 di kelas XI IPA 4 pada Kamis, 20 April 2017 dan A1-S15, A1-S16, A1-S1 di kelas XI IPA 1 pada Kamis, 3 Mei 2017 bahwa pola komunikasi scientific yang terbentuk dalam proses pembelajaran biologi dideteksi adanya hambatan proses, hambatan fisik, hambatan semantik, dan hambatan psikososial.

Pada hambatan proses, siswa mengalami hambatan dalam menyampaikan dan menerima pesan yang disebabkan oleh beberapa hal, yaitu kurang terbukanya diri sendiri, kurang percaya diri, kurang memahami konteks yang akan disampaikan, berbicara yang kurang lancar, serta perasaan rendah diri siswa yang merasa kurang pintar dibandingkan teman-teman yang lain.

Hambatan menerima pesan dialami siswa lebih dipengaruhi oleh hambatan fisik, yaitu posisi tempat duduk. Luas ruang kelas sekitar $99 \mathrm{~m}^{2}$ dan jarak siswa yang duduk di belakang dengan posisi guru di depan sekitar 7 meter. Suara guru yang berada di depan kelas kurang jelas ketika siswa mendapat giliran pada posisi tempat duduk di belakang. Posisi tempat duduk di belakang juga mempengaruhi konsentrasi belajar siswa, siswa kurang fokus mendengarkan penjelasan dan mengabaikan guru karena merasa jauh dari perhatian guru.

Selain posisi tempat duduk, peneliti juga menanyakan intensitas penggunaan sosial media untuk menggali informasi mengenai hambatan fisik siswa dalam berkomunikasi. Pada umumnya, siswa aktif menggunakan sosial media, seperti WhatsApp, BBM, Line, Instagram, dan Facebook untuk membantu mereka berkomunikasi. Siswa memilih menggunakan sosial media untuk menghindari perasaan grogi saat menyampaikan pesan jika berhadapan langsung. Hal tersebut diduga mempengaruhi inisiasi komunikasi scientific siswa dalam pembelajaran biologi karena siswa lebih nyaman menyampaikan pesan melalui media komunikasi tertulis.

Dalam hambatan proses, kegagalan komunikasi juga dipengaruhi oleh respon dari komunikan. Siswa merasa takut salah dalam menyampaikan pendapat dan takut pendapatnya tidak diterima oleh orang lain. Siswa juga takut mendapatkan respon negatif dari guru ketika menyampaikan pendapat di kelas. Respon negatif guru diduga sangat mempengaruhi keberanian siswa dalam mengemukaan pertanyaan atau pendapat ketika proses pembelajaran berlangsung, sehingga inisiasi komunikasi scientific siswa rendah. Sesuai dengan hasil penelitian McCroskey (1977) yang mengungkapkan bahwa salah satu kemungkinan besar yang menjadi penyebab terjadinya kesulitan komunikasi adalah adanya kecemasan, yaitu rasa takut menerima tanggapan atau penilaian negatif dari komunikan atau orang yang menerima pesan.

Hambatan komunikasi selanjutnya, yaitu hambatan semantik atau hambatan dalam penggunaan bahasa. Hambatan semantik dalam pembelajaran biologi yang dialami siswa adalah terdapatnya bahasa latin pada materi pembelajaran biologi. Siswa kurang menguasai bahasa latin karena menurut mereka membaca, menulis, dan menghapal bahasa latin terasa sulit. Banyak istilahistilah yang hampir serupa sehingga menyulitkan siswa untuk menghafalnya. Akan tetapi, hambatan bahasa tidak terlalu memberatkan siswa karena guru jarang menggunakan istilah-istilah berbahasa latin selama proses pembelajaran maupun dalam soal ulangan harian.

Hambatan psikososial dialami siswa di lingkungan tempat tinggal dan di sekolah, khususnya pada pembelajaran biologi. Siswa memiliki karakter belajar yang khas dalam upayanya memahami materi pelajaran dengan baik. Karakter belajar siswa berbeda-beda, akan tetapi sebagian besar membutuhkan tempat yang sepi agar dapat memahami materi pelajaran dengan baik. Jawaban yang diberikan responden menunjukkan bahwa suasana belajar biologi di kelas belum sesuai dengan karakter belajar siswa. Suasana pembelajaran yang monoton membuat siswa jenuh dan merasa mengantuk selama proses pembelajaran berlangsung. Lingkungan tempat tinggal diduga juga berpengaruh pada kemampuan komunikasi scientific siswa. Lingkungan tempat tinggal siswa yang kurang mendukung siswa belajar sesuai dengan karakter belajar yang dimiliki membuat siswa tidak semangat untuk belajar sehingga memiliki kemampuan komunikasi scientific yang rendah. 


\section{PENUTUP}

Hasil penelitian menunjukkan pola komunikasi scientific pada pembelajaran biologi adalah seimbang antara guru dan siswa sehingga tidak terdapat dominasi komunikasi oleh guru maupun siswa. Komunikasi scientific yang terjadi bersifat dua arah, akan tetapi inisiasi komunikasi scientific siswa rendah. Berdasarkan wawancara kepada siswa, diketahui penyebab kendala berkomunikasi di kelas umumya disebabkan oleh hambatan proses. Saran yang dapat diberikan dari peneliti adalah guru membuat rancangan proses pembelajaran yang sesuai untuk meningkatkan kemampuan komunikasi scientific siswa serta perlu diadakan riset lanjutan pada siswa yang rendah aktifitas komunikasi saintifiknya.

\section{DAFTAR PUSTAKA}

Chung, Y., Yoo, J., Kim, S.-W., Lee, H., Zeidler, D. L. 2014. Enhancing students, communication skills in the science classroom through socioscientific issues. International Journal of Science and Mathematics Education.

Herlanti, Y. 2006. Tanya Jawab Seputar Penelitian Pendidikan Sains. Bogor: All Right Reserved. Retrieved from http://www.repository.uinjkt.ac.id/dspace/bit stream/123456789/34107/1/YantiHerlantiBo ok1.pdf.

Inamullah, H. M., Hussain, I., Din, M. N. U. 2008. Teacher-Students Verbal Interaction At The Secondary Level. Journal of College Teavhing and Learning, 5(9), 41-44.

Lunenburg, F. C. 2010. Communication: The Process , Barriers , And Improving Effectiveness. Schooling, 1(1), 1-11.

Lunenburg, F. C. 2011. Network Patterns and Analysis: Underused Sources to Improve Communication Effectiveness. National Forum Educational Administration and Supervision Journal, 28(4), 1-7.
McCroskey, J. C. 1977. Oral Communication Apprehension: A Summary of Recent Theory and Research. Human Communication Research, 4(1), 76-96.

Mulyasa. 2006. Menjadi Guru Profesional Menciptakan Pembelajaran Kreatif dan Menyenangkan. $\quad$ Bandung: Remaja Rosdakarya.

Nielsen, K. H. 2012. Scientific Communication and the Nature of Science. Science and Education. http://doi.org/10.1007/s11191012-9475-3.

Nuryanto. 2011. Ilmu Komunikasi dalam Konstruksi Pemikiran Wilbur Schramm. Jurnal Komunikasi Masa, 4(2), 1-16.

Roshayanti, F. 2010. Model Observasi dengan VICS (Verbal Interaction Category System) sebagai Alternatif Instrumen Dalam Pelaksanaan Open Class Lesson Study. Seminar Nasional Lesson Study, 75-86.

Sharifirad, G. R., Rezaeian, M., Jazini, A., Etemadi, Z. S. 2012. Knowledge, Attitude and Performance of Academic Members Regarding Effective Communication Skills in Education. Journal of Education and Health Promotion, 1(42), 8-13. http://doi.org/10.4103/2277-9531.104812.

Sudjana, N. 2010. Dasar-Dasar Proses Belajar Mengajar. Bandung: Sinar Baru Algensindo.

Syaban, M. 2003. Asesmen Proses. Educare, 2(1), 43-51.

Tyagi, R., Mittal, P. 2013. Interactive Classroom Verbal Behaviour Patterns of Rural Science Teachers for Secondary Schools. Indian Streams Research Journal, 3(2), 1-5. http://doi.org/10.9780/22307850.

Umar, W. 2012. Membangun Kemampuan Komunikasi Matematis dalam Pembelajaran Matematika. Jurnal Ilmiah Program Studi Matematika STKIP Siliwangi Bandung, 1(1). 
Velentzas, J., Broni, G. 2014. Communication cycle: Definition, process, models and examples. Recent Advances in Financial Planning and Product Development, 117131. Retrieved from http://www.wseas.us/elibrary/conferences/2014/Istanbul/FINANCE /FINANCE-00.pdf.
Winarni, W., Santosa, S., Ramli, M. 2016. Penerapan Model Discovery Learning untuk Meningkatkan Oral Activities Siswa SMA. Bioedukasi, 9(2), 56-62. 